\title{
Patient weighting of importance of asthma symptoms
}

\author{
L M Osman, L McKenzie, J Cairns, J A R Friend, D J Godden, J S Legge, J G Douglas
}

Department of

Medicine and

Therapeutics,

University of

Aberdeen, Aberdeen

AB25 2ZD, UK

L M Osman

Health Economics

Research Unit,

University of

Aberdeen, Aberdeen

AB25 2ZD, UK

L McKenzie

J Cairns

Respiratory Medicine Unit, Aberdeen Royal Hospitals, Aberdeen

AB25 2ZN, UK

J A R Friend

D J Godden

J S Legge

J G Douglas

Correspondence to: Dr L M Osman

1.osman@abdn.ac.uk

Received 26 April 2000

Returned to authors

12 July 2000

Revised version received

2 October 2000

Accepted for publication

30 October 2000

\begin{abstract}
Background-Quality of life measures are increasingly important in evaluating outcomes in asthma. If some asthma symptoms are more troublesome to patients than others, this may affect their contribution to outcome measures. This study was designed to assess the relative importance of common symptoms in adults with asthma.
\end{abstract}

Methods-A postal survey using conjoint analysis was performed in 272 adults attending hospital outpatient clinics with moderately severe asthma. Patients were asked to chose between "symptom scenarios" offering different combinations of levels of five common asthma symptoms over one week. Two versions of the questionnaire were used with identical scenarios presenting symptoms in different orders. Different patients answered the two versions. Regression analysis was used to calculate symptom weights for daytime cough, breathlessness, wheeze and chest tightness, and sleep disturbance.

Results-Symptom order, percentage predicted peak expiratory flow (PEF), and symptoms in the week before the survey did not influence the choice of scenario. In both questionnaires patients were more likely to choose scenarios with low levels of cough and breathlessness than low sleep disturbance, wheeze or chest tightness. Regression weights for cough $(-0.52)$ and breathlessness $(-0.49)$ were twice those of wheeze $(-0.25)$, chest tightness $(-0.27)$, and sleep disturbance $(-0.25)$. For $12 \%$ of patients cough dominated patient preferences, regardless of all other symptoms. Age was inversely related to weight given by patients to breathlessness.

Conclusions-The prominence of cough among other asthma symptoms was unexpected. Daytime cough and breathlessness had greater impact for patients than wheeze or sleep disturbance. Age influenced symptom burden, with younger patients giving greater weight to breathlessness than older patients. Conjoint analysis appears to be a useful method for establishing the relative importance of common symptoms.

(Thorax 2001;56:138-142)

Keywords: conjoint analysis; cough; asthma; quality of life

Quality of life measures are increasingly important in evaluating outcomes in asthma care. ${ }^{1}$ Questionnaires used include generic measures such as the SF-36 questionnaire ${ }^{2}$ and respiratory specific measures such as the $\mathrm{St}$ George's Respiratory Questionnaire (SGRQ) ${ }^{3}$ and the Asthma Quality of Life Questionnaire (AQLQ). ${ }^{4}$ Quality of life questionnaires have been shown to be useful outcome indicators but they are lengthy to administer and score and simpler outcome measures have been suggested. Suggestions include the "symptom free days" measure ${ }^{5}$ which counts the number of diary days in which patients record no asthma symptoms, and the Jones morbidity index ${ }^{6}$ which generates a single score by adding patient ratings of severity of two symptoms and degree of limited activity in a defined recent period.

However, simpler outcome measures are based on a smaller number of indicators so the relative weight given to the components becomes more important. Quirk and Jones found variation in distress ratings between items in the SGRQ scale ${ }^{7}$ and Steen et $a l^{8}$ reported that patients' mean level of "bother" varied for different aspects of asthma. If some symptoms are more troublesome to patients than others, this may influence their contribution to the outcome measure.

Conjoint analysis, ${ }^{9}$ which was originally developed for market research into customer preferences, is a method which investigates the relative weights given by respondents to a set of attributes. We are not aware of any previous studies in which conjoint analysis has been used to assess preferences for symptoms. This investigation was undertaken to determine whether it is a suitable method for exploring patient weighting of asthma symptoms.

\section{Methods}

SCENARIO DESIGN

We based the attributes and levels used in the scenarios on symptoms used in existing outcome measures for asthma. ${ }^{6}{ }^{10}$ Symptoms identified were daytime cough, daytime breathlessness, daytime wheeze, daytime chest tightness, and sleep disturbance as a result of night time asthma symptoms. The levels chosen for the attributes are shown in table 1 .

The constructed scenarios described what most days in a week would be like using three levels of each of the five asthma symptoms. An example is given in fig 1 .

The number of possible scenarios which could be constructed from a set of five attributes each having three levels is $3^{5}=243$. An SPSS package (ORTHOPLAN) was used to obtain the minimum number of scenarios needed to obtain utility scores for each 
Table 1 Attribute levels used in the conjoint analysis questionnaire

\begin{tabular}{|c|c|}
\hline Attribute & Levels \\
\hline Cough & $\begin{array}{l}\text { No cough }(0) \\
\text { Some coughing but no restricted activities (1) } \\
\text { A lot of coughing with restricted activities (2) }\end{array}$ \\
\hline Breathlessness & $\begin{array}{l}\text { No breathlessness }(0) \\
\text { A little breathlessness but no restricted activities (1) } \\
\text { Very breathless with restricted activities }(2)\end{array}$ \\
\hline Wheeze & $\begin{array}{l}\text { No wheeze }(0) \\
\text { Some wheezing but with no restricted activities (1) } \\
\text { Very wheezy with restricted activities (2) }\end{array}$ \\
\hline Chest tightness & $\begin{array}{l}\text { Chest not tight }(0) \\
\text { A little tightness }(1) \\
\text { Chest very tight }(2)\end{array}$ \\
\hline Sleep disturbance & $\begin{array}{l}\text { No sleep disturbance }(0) \\
\text { Awoke once with cough / breathlessness (1) } \\
\text { Awoken } 2-3 \text { times with cough/breathlessness (2) }\end{array}$ \\
\hline
\end{tabular}

\begin{tabular}{|c|}
\hline \multicolumn{1}{|c|}{$\begin{array}{c}\text { Week A } \\
\text { On most days }\end{array}$} \\
\hline Some coughing \\
\hline A little breathlessness \\
\hline $\begin{array}{l}\text { Very wheezy with } \\
\text { restricted activities }\end{array}$ \\
\hline A little chest tightness \\
\hline No sleep disturbance \\
\hline
\end{tabular}

\begin{tabular}{|l|}
\hline \multicolumn{1}{|c|}{ Week B } \\
On most days \\
\hline A lot of coughing \\
\hline A little breathlessness \\
\hline No wheeze \\
\hline Chest very tight \\
\hline $\begin{array}{l}\text { Woke once with } \\
\text { cough/breathlessness }\end{array}$ \\
\hline
\end{tabular}

I would prefer

(tick the box you prefer)

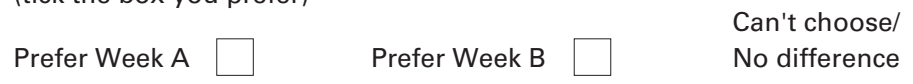

Figure 1 Layout of questionnaire.

Table 2 Scenario weightings

\begin{tabular}{|c|c|c|c|c|}
\hline \multirow[b]{2}{*}{ Pair } & \multicolumn{2}{|l|}{ Week $A$} & \multicolumn{2}{|l|}{ Week B } \\
\hline & $\begin{array}{l}\text { Levels of symptoms (cough, } \\
\text { breathlessness, wheeze, } \\
\text { chestiness, sleep) }\end{array}$ & $\begin{array}{l}\text { Unweighted } \\
\text { score }\end{array}$ & $\begin{array}{l}\text { Levels of symptoms (cough, } \\
\text { breathlessness, wheeze, } \\
\text { chestiness, sleep) }\end{array}$ & $\begin{array}{l}\text { Unweighted } \\
\text { score }\end{array}$ \\
\hline 1 & $(2,0,2,1,2)$ & 7 & $(1,0,0,0,0)$ & 1 \\
\hline 2 & $(0,1,1,1,0)$ & 3 & $(2,0,1,0,0)$ & 3 \\
\hline 3 & $(0,0,0,2,0)$ & 2 & $(1,2,1,2,2)$ & 8 \\
\hline 4 & $(1,1,2,1,0)$ & 5 & $(2,1,0,2,1)$ & 6 \\
\hline 5 & $(2,0,2,2,0)$ & 6 & $(0,2,2,0,1)$ & 5 \\
\hline 6 & $(2,2,0,1,0)$ & 5 & $(2,0,1,1,1)$ & 5 \\
\hline 7 & $(2,2,0,1,0)$ & 5 & $(0,0,0,1,2)$ & 3 \\
\hline 8 & $(1,0,0,1,1)$ & 3 & $(2,1,0,0,2)$ & 5 \\
\hline
\end{tabular}

Pairs 1 and 3 were test scenarios for rational choice behaviour.

attribute. This generated 16 scenarios which were then used to construct a set of eight pairs.

Two of the eight scenario pairs were deliberately chosen as a means of testing for a minimal level of rational choice behaviour in patient responses. Complete "rationality" in choice was not required, but we would expect individuals to reject scenarios that had very much higher symptoms than their pair. Thus, in table 2 , in scenario pair 1 week B should always be preferred to week $A$, and in pair 3 week A should always be preferred to week B. Eleven patients were excluded on this basis from the analysis. This rate of "non-rational" choice is lower than rates found in other conjoint analysis and preference studies. ${ }^{11}$

Patients' responses might be influenced by the order in which attributes are presented in the scenarios. For this reason two different questionnaires were used with the order of attributes in scenarios changed. Cough and sleep disturbance, which appeared first and last in questionnaire 1 , were placed third and fourth in questionnaire 2 .

SURVEYS

Questionnaires were mailed to patients with asthma who had attended chest clinics throughout the Grampian region. All patients were or had been in a "shared care" scheme ${ }^{12}$ between the hospital adult clinic and general practice. These patients are managed by their general practice with one annual review at the specialist clinic. Thus, the population represented a group with asthma of moderate severity whose asthma was sufficiently severe to warrant a chest clinic referral but who were now mainly returned to management in the community.

As described above, two surveys were carried out. The first survey was sent out to patients in shared care who were due to attend a GP or chest clinic regular review. The second survey was sent to all remaining patients in the shared care scheme and to patients who had been returned to clinic care. The surveys used different versions of the questionnaire in order to control for possible ordering effects of symptom presentation. Both questionnaires presented the same eight pairs of scenarios to patients and asked them to choose which they would prefer, or to indicate that they had no preference. In questionnaire 1 patients were presented with symptoms in the order: daytime cough, daytime breathlessness, daytime wheeze, chest tightness, sleep disturbance; and in questionnaire 2 the order was: daytime breathlessness, daytime wheeze, sleep disturbance, daytime cough, chest tightness.

\section{CLINICAL DATA}

The questionnaires included a morbidity section asking about asthma symptoms in the week before completing the survey. Information from hospital and GP records was also collected for patient peak expiratory flow (PEF) measured within the last year, and number of oral steroid courses in the three months before the survey. Percentage predicted PEF was calculated, adjusting for age, sex and height. ${ }^{13}$

\section{ANALYSIS OF DATA}

Symptom weights

Ordered probit regression was used to test the null hypothesis of equal weights for symptoms. An ordered probit model was able to use the data from all three response categories for each symptom attribute. A random effect model was used as there were multiple observations (8) from each respondent. As described earlier, 16 scenarios had been generated, to be used in eight pairs. All of these were needed to test the model, including the four which had been paired in such a way so as to test "rationality". All responses from all participants were used except the 11 participants who were excluded because their responses were "non-rational", as 
Table 3 Mean (SD) characteristics of patients

\begin{tabular}{lccc}
\hline & $\begin{array}{l}\text { Total } \\
(n=162)\end{array}$ & $\begin{array}{l}\text { Survey 1 } \\
(n=76)\end{array}$ & $\begin{array}{l}\text { Survey 2 } \\
(n=86)\end{array}$ \\
\hline Age $^{1}$ & $52.9(16.4)$ & $53.7(15.7)$ & $51.1(14.3)$ \\
$\%$ predicted PEF $(\mathrm{n}=128)$ & $69.1(19.8)$ & $70.8(19.45)$ & $68.0(19.5)$ \\
Oral steroid courses in past 3 months $(\mathrm{n}=136)^{3}$ & $0(0-1)$ & $0(0-1)$ & $0(0-1)$ \\
Current symptoms in past week, $\mathrm{n}(\%)^{2}$ & $90(58 \%)$ & $42(57 \%)$ & $48(59 \%)$ \\
$\quad$ Daytime cough & $105(67 \%)$ & $48(66 \%)$ & $57(69 \%)$ \\
Daytime breathlessness & $87(56 \%)$ & $38(51 \%)$ & $49(60 \%)$ \\
Daytime wheeze & $67(43 \%)$ & $30(39 \%)$ & $37(46 \%)$ \\
$\quad$ Chest tightness & $69(44 \%)$ & $26(34 \%)$ & $43(48 \%) \dagger$ \\
$\quad$ Sleep disturbance & & & \\
\hline
\end{tabular}

'Respondents' ages ranged from 15 to 86 years.

$2 \%$ allows for non-response to the survey.

${ }^{3}$ Median (IQR).

$\mathrm{tp}=0.02$.

Table 4 Number (\%) of respondents whose choices were determined by a dominant symptom $(n=162)$

\begin{tabular}{lc}
\hline Daytime cough (1) (3) & $21(13.0 \%)$ \\
Daytime breathlessness (2) (1) & $4(2.5 \%)$ \\
Daytime wheeze (3) (2) & $0(0 \%)$ \\
Chest tightness (4) (5) & $1(0.6 \%)$ \\
Sleep disturbance (5) (4) & $2(1.2 \%)$ \\
\hline
\end{tabular}

*Numbers in brackets show the order of presentation of symptoms in questionnaire 1 and questionnaire 2 scenarios.

discussed earlier. The model used was based on the formula:

$$
\begin{gathered}
\mathrm{UA}-\mathrm{UB}=\beta_{1} \mathrm{DC}+\beta_{2} \mathrm{DB}+\beta_{3} \mathrm{DW} \\
+\beta_{4} \mathrm{DCT}+\beta_{5} \mathrm{DS}
\end{gathered}
$$

where UA - UB is the difference in utility between the two scenarios (week $\mathrm{A}$ and week B). DC, DB, DW, DCT, and DS are the difference variables for the attributes cough, breathlessness, wheeze, chest tightness, and sleep disturbance, respectively.

Student's $t$ tests were used for comparison of means in parametric data and the $\chi^{2}$ test for non-parametric analysis.

\section{Covariates}

Dummy variable interaction terms were added to the model in order to assess whether age, asthma severity, or sex were significant covariates for symptom weights.

\section{Dominance}

Regression analysis tests a model of additive symptom weights. However, an alternative "dominance" model is possible in which some people always prefer the scenario with the lowest level of a specific symptom, regardless of the other symptoms. Patients were assessed to establish if their choices fitted a dominance model.

\section{Results}

A total of 272 questionnaires were sent out of which 182 were returned (82 version 1 (78\%) and 100 version $2(49 \%)$ ). Survey 1 was sent

Table 5 Results from the ordered probit regression analysis for questionnaire 1, questionnaire 2, and merged data

\begin{tabular}{llll}
\hline & Questionnaire 1 $(n=608)$ & Questionnaire 2 $(n=688)$ & Total \\
\hline Daytime cough & $-0.48(0.04)$ & $-0.55(0.04)$ & -0.52 \\
Daytime breathlessness & $-0.48(0.04)$ & $-0.50(0.04)$ & -0.49 \\
Daytime wheeze & $-0.25(0.07)$ & $-0.24(0.07)$ & -0.25 \\
Chest tightness & $-0.24(0.07)$ & $-0.30(0.07)$ & -0.27 \\
Sleep disturbance & $-0.26(0.05)$ & $-0.24(0.05)$ & -0.25 \\
\hline
\end{tabular}

The $\chi^{2}$ statistic (95\% critical value 11.07) was used for testing the restriction that the coefficients are the same for surveys 1 and 2 . Likelihood ratio $(L R)=3.54$, hence the $\mathrm{H}_{0}$ (no difference between weights in the two surveys) cannot be rejected. All $\mathrm{p}$ values $\leqslant 0.001$. with the regular review questionnaire which patients complete every three months and survey 2 was sent outside normal review to the remaining shared care patients. Twenty questionnaires were excluded from the final analysis, nine because they were incomplete and 11 which gave "non-rational choices" in the two test scenarios, as described above. This gave a usable response rate of $64 \%$.

Table 3 shows the characteristics of the respondents. Ages ranged from 15 to 86 years with a mean age of 53 years. Mean (SD) percentage predicted PEF was 69.1 (19.8)\%. In the week before the survey $58 \%$ of the respondents were troubled by cough, $67 \%$ by breathlessness, and $44 \%$ by night time waking due to asthma symptoms. The two survey groups did not differ in lung function, age, or the use of oral steroids in the past 12 months, but the second survey group was more likely to have had sleep disturbance in the week before completing the questionnaire.

\section{DOMINANCE ANALYSIS}

Table 4 shows the proportion of patients who always preferred scenarios with the lowest level of a particular symptom, regardless of the levels of the other symptoms. Cough appeared to be a dominant symptom for some patients but, in general, a simple dominance model did not hold.

REGRESSION ANALYSIS

As a dominance model did not fit the choices of the majority of patients, regression analysis was used to establish relative weights of symptoms in the paired scenarios (table 5). All symptoms contributed significantly to patient preferences. However, cough and breathlessness were weighted twice as highly as the other symptoms. This difference in weighting was significant and consistent in both versions of the questionnaire.

EFFECT OF COVARIATES ON SYMPTOM WEIGHTS Current symptoms and percentage predicted PEF were not significant covariates of symptom weights but the effect of age was statistically significant for breathlessness weighting. Using the older age group (65+ years) as the baseline with the two younger age groups ( $<46$ years and 46-64 years) as reference cases, the youngest age group had significantly greater weights for breathlessness $(-0.65$ compared with $-0.50 ; \mathrm{p}<0.01)$.

\section{Discussion}

The results of this study support the hypothesis that patients perceive some asthma symptoms as more troublesome than others. In order to obtain lower levels of cough and breathlessness, patients will trade off higher levels of wheeze, sleep disturbance, and chest tightness. For a significant minority of patients cough is the symptom of overriding concern, regardless of other symptoms. Symptom preferences were independent of sex, percentage predicted PEF, or current symptoms, but younger patients gave greater negative weight to breathlessness and chest tightness than older patients. 
We obtained reasonable response rates to the questionnaires and few patients were unable to make consistent choices. There was consistency of symptom weighting across patients in spite of differences in the level of asthma symptoms, and current symptoms did not influence the perceived importance of symptoms. This suggests that this method of asking patients to choose between scenarios is valid and can be a useful technique for determining symptom preferences.

We were surprised by the dominance of cough in patient perception of symptom importance. Cough may be more problematic for patients because it responds less well to treatment with bronchodilators than wheeze, chest tightness, and breathlessness. Alternatively, wheeze, chest tightness, and breathlessness may overlap in some patients and cough may therefore be a more distinctive or dominant symptom for these patients. Few studies have specifically assessed cough as a primary outcome variable. Cough may be neglected in assessing quality of life in asthma because it has special characteristics. The causes of cough are multifactorial, ${ }^{14}$ and cough is difficult to measure reliably in patients. It is not clear how strongly cough relates to other outcomes such as likelihood of an acute exacerbation.

Reduction in cough is less likely to be used as an indicator of successful treatment in asthma than reduction in sleep disturbance or wheeze. However, cough is a major reason for patient presentation in general practice. ${ }^{15}$ Chronic cough is significantly associated with psychological symptoms ${ }^{16}$ and poor quality of life, ${ }^{17}$ and successful treatment of cough is associated with significant improvement in psychosocial outcomes. ${ }^{15}$

A syndrome of "cough variant asthma" has been proposed in which cough is the major presenting symptom. Patients do not report significant wheeze but airway reversibility is present and corticosteroids result in significant symptomatic improvement. ${ }^{18}$ The mean percentage fall in forced expiratory volume in one second $\left(\mathrm{FEV}_{1}\right)$ at which wheezing is first detected is significantly greater in patients diagnosed with "cough variant asthma" than in those with "classic" asthma, ${ }^{19}$ which suggests that patients with "cough variant asthma" may represent a subset of asthmatic subjects whose airways are less likely to develop audible wheeze. If this syndrome exists, such patients may give greater weight to cough as a symptom. In the present study patients were not selected as having "cough variant asthma". There was no emphasis on cough in their referral, presentation, or diagnosis. Cough was not the most common symptom reported by these patients in the week before carrying out either survey and, as noted above, the weights for symptoms derived from scenario preferences were not significantly influenced by patients' current symptoms, including cough. Wheeze was more common than cough in most of these patients. It seems unlikely that the weight given to cough is due to a high presence of "cough variant asthma" in the sample.
We were also surprised by the relatively low weighting for sleep disturbance and wheeze. It appeared that patients would trade higher levels of both of these symptoms for lower levels of cough and breathlessness. Important diagnostic symptoms for physicians are perhaps less important quality of life symptoms for patients.

Breathlessness was significant for patients, equalling the weight of cough in both surveys. Younger patients gave significantly greater weight to breathlessness and chest tightness than older patients. Similar studies performed in younger patients could establish how powerful a covariate age is for symptom weighting. This could have important implications for the interpretation of existing outcome measures and the identification of more sensitive measures.

Conjoint analysis was developed to investigate preferences in decision making in marketing, but it may also be a powerful tool to assist our understanding of patient decision making. For instance, using conjoint analysis Singh et $a l^{20}$ found that, for parents' choice of treatment, the degree of perceived risk of growth hormone therapy had nine times the weight of ease of use and 2.5 times the weight of cost. In the present study the specific finding of the importance of cough to patients was unexpected but was robust across two surveys with separate groups of patients. In the future, conjoint analysis could help to explore the weight patients give to different aspects of treatments and trade off between possible benefits and perceived risks of treatment in a range of chronic illnesses. Jones et $a l^{1}$ have pointed out that there is a need for simple asthma outcome measures for primary care which are not only valid in terms of their relationship with lung function but also in terms of their psychological impact on patients. Current outcome measures may not emphasise sufficiently the weight of symptoms as perceived by patients rather than their health carers.

The authors thank the patients who took part in the study; Mrs J Fiddes, Asthma Care Coordinator, Aberdeen Royal Infirmary for her coordination of both surveys; and Ms Christine Calder, Asthma Care Nurse and Ms M Jaffray, Research Assistant, for their assistance with the study.

This study was supported by the NHS R \& D Delivery of Care in Asthma Programme, UK, reference AM1/06/004. The Health Economics Research Unit is funded by the Chief Scientist Officenomics Research (SODoH). The views expressed in this paper are those of the (SODoH). The views exp
authors and not SODoH.

Conflicts of interest: none.

1 Rutten-Van Molken MPMH, Custers F, Van Doorslaer EKA, et al. Comparison of performance of four instru-
EKA EKA, et al. Comparison of performance of four instru-
ments in evaluating the effects of salmeterol on asthma ments in evaluating the effects of salmete
quality of life. Eur Respir f $1995 ; 8: 888-98$.

quality of life. Eur Respir $\mathcal{F} 1995 ; 8: 888-98$.
2 Ware JE. Measuring patients' views: the optimum outcome measure. SF-36, a valid, reliable assessment of health from the patients' point of view. BMF 1993;306:1429-30

3 Jones PW, Quirk FH, Baveystock CM. The St George's respiratory questionnaire. Respir Med 1991;85:25-31.

4 Juniper EF, Guyatt GH, Ferrie PJ, et al. Measuring quality of life in asthma. Am Rev Respir Dis 1993;147:832-8.

5 Sculpher MJ, Buxton MJ. The episode-free day as a composite measure of effectiveness. Pharmoeconomics 1993; 4:345-52.

6 Jones K, Cleary R, Hyland M. Predictive value of a simple asthma morbidity index in a general practice population. $\mathrm{Br}$ f Gen Pract 1999;49:23-6.

7 Quirk FH, Jones PW. Patients' perception of distress due to symptoms and effects of asthma on daily living and an 1990;79:17-21. 
8 Steen N, Hutchinson A, McColl E, et al. Development of a symptom based outcome measure for asthma. BMF 1994, symptom based

9 Ryan M, McIntosh E, Shackley P. Methodological issues in the application of conjoint analysis in health care. Health Econ 1998;7:373-8.

10 Bai J, Peat JK, Berry G, et al. Questionnaire items that predict asthma and other respiratory conditions in adults. Chest 1998;114:1343-8.

11 Vick S, Scott A. Agency in health care. Examining patients' preferences for attributes of the doctor-patient relationship. F Health Econ 1998; 17:587-605.

12 Osman LM, Abdalla MI, Russell IT, et al. Integrated care for asthma: matching care to the patient. Eur Respir ₹ 1996;9: $444-8$.

13 Nunn AJ, Gregg I. New regression equations for predicting peak expiratory flow in adults. $B M \mathcal{F} 1989 ; 298: 1068-70$.

14 Irwin RS, Boulet LP, Cloutier MM, et al. Managing cough as a defense mechanism and as a symptom. A consensus panel report of the American College of Chest Physicians. Chest 1998;114:133-81S.

15 French CL, Irwin RS, Curley FJ, et al. Impact of chronic cough on quality of life. Arch Intern Med 1998;158:165761.
16 Carney IK, Gibson PG, Murree-Allen K, et al. A systematic evaluation of mechanisms in chronic cough. Am $\mathcal{F}$ Respir Crit Care Med 1997;156:211-6.

17 Vergnenegre A, Martin J, D'Arco X, et al. Effect of respiratory symptoms and obstruction of the upper airways on quality of life in a rural population. Rev Malad Respir 1995; 12:615-21.

18 Irwin RS, French CT, Smyrnios NA, et al Interpretation of positive results of a methacholine inhalation challenge and 1 week of inhaled bronchodilator use in diagnosing and treating cough-variant asthma. Arch Intern Med 1997;157: 1981-7.

19 Koh YY, Chae SA, Min KU. Cough variant asthma is associated with a higher wheezing threshold than classic asthma. Clin Exp Allergy 1993;23:696-701.

20 Singh J, Cuttler L, Shin M, et al. Medical decision-making and the patient: understanding preference patterns for growth hormone therapy using conjoint analysis. Med Care 1998;36:AS31-45.

21 Jones K, Cleary R, Hyland M. Associations between an asthma morbidity index and ideas of fright and bother in a community population. Respir Med 1999;93:515-9. 